\title{
TANDEM-X: DEM CALIBRATION CONCEPT
}

\author{
Birgit Wessel $^{a}$, Astrid Gruber ${ }^{a}$, Jaime Hueso González ${ }^{b}$, Markus Bachmann $^{b}$, Anna Wendleder $^{c}$ \\ ${ }^{a}$ German Remote Sensing Data Center, German Aerospace Center (DLR), Oberpfaffenhofen, 82234 Wessling, Germany, \\ ${ }^{b}$ Microwaves and Radar Institute, German Aerospace Center (DLR), Oberpfaffenhofen, 82234 Wessling, Germany \\ ${ }^{c}$ Remote Sensing Technology, Technische Universitaet Muenchen, 80333 Munich, Germany \\ Email: <name.surname>@dlr.de
}

\begin{abstract}
The TanDEM-X mission will derive a global digital elevation model (DEM) with satellite SAR interferometry. The aimed accuracies are an absolute height error of $10 \mathrm{~m}$ and a relative height error of $2 \mathrm{~m}$ for $90 \%$ of the data. This requires a correction of the elevation heights after interferometric processing by residual systematic DEM errors. The estimation and correction of these errors is called DEM calibration. This paper gives an overview of the DEM calibration strategy within the TanDEM-X mission. First, the error sources and their influence on the DEM are determined by a functional description. Then, a strategy for a new block adjustment of DEMs is set up and evaluated with simulated and real DEMs.
\end{abstract}

Keywords- TanDEM-X, DEM calibration, least-squares adjustment

\section{INTRODUCTION}

The mission scenario for TanDEM-X is designed to obtain a global DEM of the whole earth within mission time (3 years) with the specified accuracies:

TABLE I

TANDEM-X DEM SPECIFICATIONS

\begin{tabular}{|l|l|l|}
\hline Requirement & Specification & Accuracy \\
\hline $\begin{array}{l}\text { Absolute vertical accuracy } \\
\text { (global) }\end{array}$ & $90 \%$ linear error & $10 \mathrm{~m}$ \\
\hline $\begin{array}{l}\text { Relative vertical accuracy } \\
(100 \mathrm{~km} \times 100 \mathrm{~km})\end{array}$ & $\begin{array}{l}90 \% \text { linear point-to- } \\
\text { point error }\end{array}$ & $\begin{array}{l}2 \mathrm{~m}(\text { slope }<20 \%) \\
4 \mathrm{~m}(\text { slope }>20 \%)\end{array}$ \\
\hline
\end{tabular}

To fulfil these accuracies the designed mission plan foresees that all land surfaces will be covered at least twice with different heights of ambiguity to minimize the height error by averaging DEM acquisitions and to facilitate the phase unwrapping by multi-baseline methods. The length of the data takes will be maximized within the resource limits in order to simplify the adjustment by reducing the number of DEM acquisitions. The DEM calibration of TanDEM-X is based on two additional data sources: overlaps between neighboured DEMs and absolute height references. On the basis of this information a strategy for DEM calibration is developed.

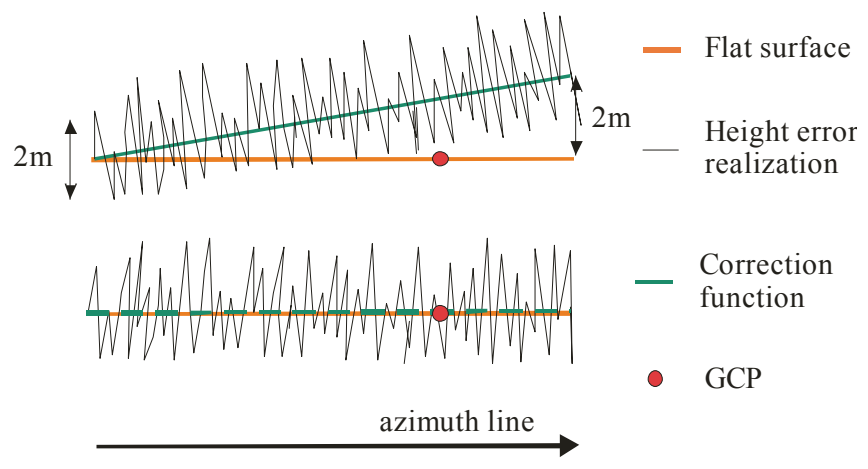

Figure 1. Example for DEM calibration: A flat area is measured with a random height error of $2 \mathrm{~m}$ and a tilt and offset error of $2 \mathrm{~m}$. The corresponding correction function shall correct these systematic height errors.

The challenge of calibrating the TanDEM-X DEM lies in the magnitude of the systematic errors: these errors are in the same order like the random error of about $2 \mathrm{~m}$. In order to estimate and correct the remaining systematic offsets and tilts (Fig. 1), the nature of the error sources has been carefully analysed. A functional model has been set up for the residual systematic errors in the interferometric DEM (Chapter 2). This allows the design of a subsequent DEM calibration strategy (Chapter 3). For the estimation of the corrections a least-squares adjustment of adjacent interferometric DEMs over a certain earth region is designed. In Chapter 4 the adjustment is tested and evaluated by a simulated, larger test site and experimental E-SAR DEM data.

The goal of the DEM calibration concept is to refine the strategy for the data acquisition plan [1] and to set a robust basis for the "DEM Mosaicking and Calibration Processor" [2], which will adjust the interferometric DEMs globally to produce the TanDEM-X DEM product.

\section{MODEL FOR SYSTEMATIC DEM ERRORS}

The main sources of residual systematic height errors can be divided into three groups [1]: random phase errors, inaccuracies in the baseline determination, and residual 
instrument phase drifts. The random phase error is a high frequency error and can be regarded as noise. A noise level slightly above $2 \mathrm{~m}$ is expected for one interferometric TanDEM-X DEM acquisition. In contrary the baseline inaccuracies and the systematic instrument drifts introduce mainly low frequency errors in terms of the datatake length. Baseline errors parallel to the line of sight cause a vertical displacement, similar to an azimuth modulation, and a tilt of the DEM. Due to the helix formation flight of both TanDEM-X satellites the baseline length changes slowly during one datatake. This introduces non-linear components and torsion.

These systematical error characteristics can be approximately expressed by a third order polynomial for one TanDEM-X DEM acquisition

$$
g_{I}(r g, a z)=a_{I}+b_{I} r g+c_{I} a z+d_{I} r g a z+e_{I} a z^{2}+f_{I} a z^{3},
$$

where, $I$ is the index of the DEM acquisition and $a-f$ are the unkown error parameters. This error description was found through a statistical study. Main influences are the height offset and slopes in range and azimuth that cause errors above $0.5 \mathrm{~m}$. Furthermore, torsion between range and azimuth and second and third order errors in azimuth play a minor role.

\section{DEM CALIBRATION CONCEPT}

The goal of the DEM calibration is to estimate systematic height errors to fulfil the required height accuracies (Table I). The DEM calibration concept outlines the strategy for this calibration. In this section a concept is introduced that will be evaluated in the next section.

For the DEM calibration it is assumed that each DEM acquisition is distorted by the errors expressed in Eq. (1). This allows the estimation of the errors by a least-squares adjustment of adjacent DEM acquisitions. Prerequisite for the adjustment is the availability of suitable ground control points to assess the absolute height error offset with respect to WGS84. Also, reliable tie-points, i.e. identical points in overlapping DEM areas, are needed, to fulfil the strong relative vertical requirement of a $2 \mathrm{~m}$ trend error in an area of $100 \mathrm{~km}$.

\subsection{Least squares adjustment approach}

The polynomial correction parameters of Eq. (1) will be estimated within the least-squares adjustment. As shown in Fig. 2 the idea of this adjustment is that the heights in overlapping areas should be nearly identical, apart from the random noise, after the error function is applied.

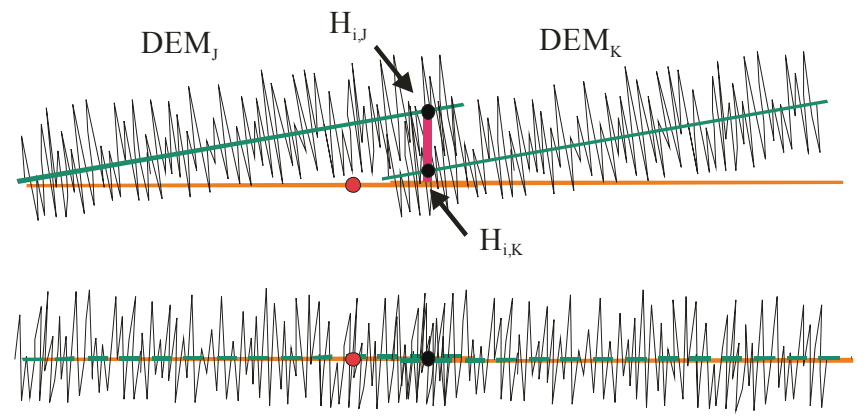

Figure 2. DEM Calibration should adjust the heights in the way that $\mathrm{H}_{\mathrm{i}, \mathrm{J}}$ on $\mathrm{DEM}_{\mathrm{J}}$ and $\mathrm{H}_{\mathrm{i}, \mathrm{K}}$ on $\mathrm{DEM}_{\mathrm{K}}$ are the same and that the surface goes through the GCPs.

$$
H_{i, J}+v_{i, J}=H_{i, K}+v_{i, K},
$$

where $\mathrm{H}$ are the heights of DEM $J$ resp. DEM $K$ and $v$ the residuals. The observables for the adjustment $(L)$ are the distorted elevation values at the tie-points.

$$
L=H_{i, I} \text { with } \hat{H}_{i, I}=H_{i, I}+g_{I}(r g, a z)
$$

For building adjustable functional equations a function has to be found that expresses this relationship, contains the unknown coefficients $X(a-f)$ and is additionally independent from the terrain height. Against this background height differences are introduced. The observation equation Eq. (2) follows the functional description for adjustment with constraints $\varphi(\widetilde{L}, \widetilde{X})=0$ :

$\left[H_{i, J}+\hat{g}_{J}(r g, a z)\right]-\left[H_{i, K}+\hat{g}_{K}(r g, a z)\right]=0$

This equation will be set up for each tie-point. The advantage of this method is that the correction parameters can be found independent from the terrain. Height offsets to WGS84 are estimated by introducing GCPs into the functional model in the same way as observables. All observables have accuracies that are used as weights for the stochastic model. The weights for the tie-point heights are taken from the height error. The weights for the GCPs should be one order higher to influence the adjustment.

\subsection{Calibration reference data}

As mentioned before, GCPs and tie-points play an important role for the DEM calibration. Therefore, they should be selected carefully according to the accuracy.

\subsubsection{Tie-point concept}

The requirements for tie-points are that identical points are chosen in at least two overlapping DEMs, a good distribution and a high reliability regarding the height error is given. The DEM acquisition length is about 500 to 
$1000 \mathrm{~km}$ in azimuth and about $30 \mathrm{~km}$ in range. The overlap area to adjacent across-track DEMs is at least $3 \mathrm{~km}$. A good distribution is realized via a regular grid and a subsequent selection process afterwards. A search for prominent features would be very time-consuming and even not successful in featureless regions. So the tie-points are evenly distributed in each overlap. In order to derive a good tie-point an image chip in the dimension of about 100 by 100 pixels is extracted. Inside the chip the most appropriate location for the tie-point is evaluated, in the way, that the DEM is statistically analyzed and the noise (height error) and the amplitude data are taken into account. The final tiepoint height will be averaged over e.g. $3 \times 3$ pixel to reduce the noise once more. Additional information can support the selection process, e.g. previously generated height discrepancy masks, water masks, and shadow/layover masks, so regions can be excluded.

\subsubsection{Ground control points}

The absolute height references have to be adequately distributed either. Coverage on all significant isolated land masses and a controlled accuracy are pursued, with the aim of guaranteeing the success of the DEM calibration. This can be achieved by using global data sets, which provide very useful information especially in regions of the planet, where the access to height data is limited or unreliable. Above this, GCPs should have an accuracy of $1 \mathrm{~m}$ or better. Reference information in open terrain is preferable, because uncertainties between terrain and surface models do not need to be considered.

The ICESat space-borne laser altimeter data [3] provide accurate, globally distributed height information as well as evaluation and classification information for each measurement point. ICESat will already provide a good absolute accuracy of up to $14 \mathrm{~cm}$ (theoretically) and a good global coverage for hooking in the DEM. For ICESat points all underlying DEM pixels under the $65 \mathrm{~m}$-ICESat-footprint are averaged in order to achieve a comparable height value. This averaging is done according to a laser specific weighting function (energy characteristic), which has also the advantage to reduce the noise of the corresponding DEM height value significantly. ICESat will be the main height reference source for TanDEM-X. Above this, locally high resolution DEMs, ground calibration targets like corner reflectors, or GPS measurements can be introduced into the adjustment.

\subsection{Verification}

For a final quality check of the DEM calibration verification is foreseen that includes significant tests and the verification of the vertical accuracy against reference data.

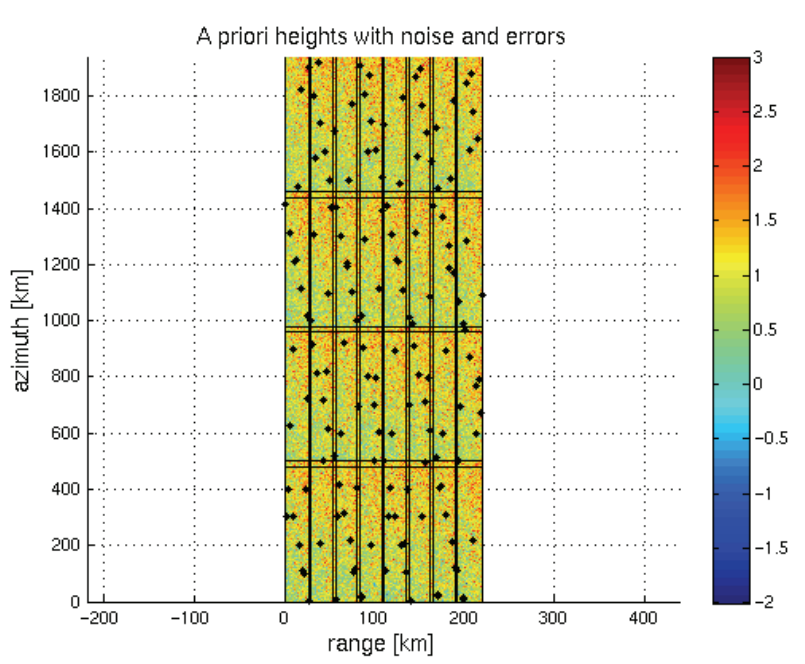

Figure 3. Simulated DEMs: Adjacent DEMs with vertical offsets and tilts in the scale of meters that overlap each other in range and azimuth; GCPs in black dots.

For this purpose verification data are needed that were not used during the calibration and at best measured by an independent system. For TanDEM-X GPS-tracks will be used. These GPS-tracks have to be measured world-wide to verify the accuracies of the TanDEM-X DEM. To check the accuracies after DEM calibration the GPS-tracks are postprocessed to a vertical precision of $0.5 \mathrm{~m}$ to verify the absolute height accuracy of $10 \mathrm{~m}$, respectively relative height accuracy of $2 \mathrm{~m}$.

\section{EVALUATION OF THE CONCEPT}

\subsection{Adjustment results on simulated data}

In order to evaluate the DEM calibration concept adjustments on simulated distorted DEM data have been carried out. For this task, a test area of $8 \times 4$ data takes (each $30 \times 500 \mathrm{~km}$ wide, see Fig. 3) were simulated with noise and height errors as described in Eq. (1). In our simulations the following parameters were varied:

- $\quad$ noise of tie-points $(0.4 \mathrm{~m}, 0.7 \mathrm{~m}, 2 \mathrm{~m})$

- distance between two adjacent ICESat ground tracks: at the equator $80 \mathrm{~km}$, in temperate zones $55 \mathrm{~km}$, and at the pole $15 \mathrm{~km}$

- distance between ICESat points in flight direction $(1000 \mathrm{~km}, 100 \mathrm{~km}, 10 \mathrm{~km})$

- different dense tie-point grids $(2 \times 10 \mathrm{~km}, 1 \times 5 \mathrm{~km}$, $1 \times 1 \mathrm{~km})$

- $\quad$ number of simulated and estimated parameters (1, $2,3,4,5,6)$

- number of crossing orbits (none, one, two (distance of $1000 \mathrm{~km}$ ) and three (distance of $500 \mathrm{~km})$ crossing orbits) 
TABLE II

ESTIMATED COEFFICIENTS BY ADJUSTMENTS OF SIMULATED DEMS

\begin{tabular}{|c|c|c|c|c|c|c|c|c|c|}
\hline \multirow[b]{2}{*}{0} & \multicolumn{3}{|c|}{ EQUA } & \multicolumn{3}{|c|}{ TMPZ } & \multicolumn{3}{|c|}{ POLE } \\
\hline & 0.4 & 0.7 & 2.0 & 0.4 & 0.7 & 2.0 & 0.4 & 0.7 & 2.0 \\
\hline & a & a & a & $\mathrm{a}$ & a & a & $\mathrm{a}$ & a & a \\
\hline $\begin{array}{c}\text { GCP } \\
1000 \\
\text { km }\end{array}$ & $\begin{array}{l}\text { abc } \\
\text { abcd } \\
\text { abcde } \\
\text { abcdef }\end{array}$ & $\begin{array}{l}\text { abc } \\
\text { abcd } \\
\text { abcde } \\
\text { abcdef }\end{array}$ & $\begin{array}{l}\text { abc } \\
\text { abcd } \\
\text { abcde } \\
\text { abcdef }\end{array}$ & $\begin{array}{l}\text { abc } \\
\text { abcd } \\
\text { abcde } \\
\text { abcdef }\end{array}$ & $\begin{array}{l}\text { abc } \\
\text { abcd } \\
\text { abcde } \\
\text { abcdef }\end{array}$ & $\begin{array}{l}\text { abc } \\
\text { abcd } \\
\text { abcde } \\
\text { abcdef }\end{array}$ & $\begin{array}{l}\text { abc } \\
\text { abcd } \\
\text { abcde } \\
\text { abcdef }\end{array}$ & $\begin{array}{l}\text { abc } \\
\text { abcd } \\
\text { abcde } \\
\text { abcdef }\end{array}$ & $\begin{array}{l}\text { abc } \\
\text { abcd } \\
\text { abcde } \\
\text { abcdef }\end{array}$ \\
\hline $\begin{array}{c}\text { GCP } \\
100 \\
\text { km }\end{array}$ & \begin{tabular}{|l} 
\\
abc \\
abcd \\
abcde \\
abcdef
\end{tabular} & $\begin{array}{l}\text { a } \\
\text { abc } \\
\text { abcd } \\
\text { abcde } \\
\text { abcdef }\end{array}$ & $\begin{array}{l}\text { a } \\
\text { abc } \\
\text { abcd } \\
\text { abcde } \\
\text { abcdef }\end{array}$ & $\begin{array}{l}\text { a } \\
\text { abc } \\
\text { abcd } \\
\text { abcde } \\
\text { abcdef }\end{array}$ & $\begin{array}{l}\text { a } \\
\text { abc } \\
\text { abcd } \\
\text { abcde } \\
\text { abcdef }\end{array}$ & $\begin{array}{l}\text { a } \\
\text { abc } \\
\text { abcd } \\
\text { abcde } \\
\text { abcdef }\end{array}$ & $\begin{array}{l}\text { a } \\
\text { abc } \\
\text { abcd } \\
\text { abcde } \\
\text { abcdef }\end{array}$ & $\begin{array}{l}\text { a } \\
\text { abc } \\
\text { abcd } \\
\text { abcde } \\
\text { abcdef }\end{array}$ & $\begin{array}{l}\text { a } \\
\text { abc } \\
\text { abcd } \\
\text { abcde } \\
\text { abcdef }\end{array}$ \\
\hline $\begin{array}{c}\text { GCP } \\
10 \\
\text { km }\end{array}$ & $\begin{array}{l}\mathrm{a} \\
\mathrm{abc} \\
\mathrm{abcd} \\
\text { abcde } \\
\text { abcdef }\end{array}$ & $\begin{array}{l}a \\
\text { abc } \\
\text { abcd } \\
\text { abcde } \\
\text { abcdef }\end{array}$ & $\begin{array}{l}\text { a } \\
\text { abc } \\
\text { abcd } \\
\text { abcde } \\
\text { abcdef }\end{array}$ & $\begin{array}{l}\text { a } \\
\text { abc } \\
\text { abcd } \\
\text { abcde } \\
\text { abcdef }\end{array}$ & $\begin{array}{l}\mathrm{a} \\
\mathrm{abc} \\
\mathrm{abcd} \\
\mathrm{abcde} \\
\text { abcdef }\end{array}$ & $\begin{array}{l}\text { a } \\
\text { abc } \\
\text { abcd } \\
\text { abcde } \\
\text { abcdef }\end{array}$ & $\begin{array}{l}\text { a } \\
\text { abc } \\
\text { abcd } \\
\text { abcde } \\
\text { abcdef }\end{array}$ & $\begin{array}{l}\mathrm{a} \\
\mathrm{abc} \\
\mathrm{abcd} \\
\mathrm{abcde} \\
\text { abcdef }\end{array}$ & $\begin{array}{l}\text { a } \\
\text { abc } \\
\text { abcd } \\
\text { abcde } \\
\text { abcdef }\end{array}$ \\
\hline
\end{tabular}

For each of these configurations the least-squares adjustment described in Ch. 3 is carried out. The differences between the initially simulated and the resultant estimated height errors are calculated. If the maximum difference is less than the simulated height error at the edges of the data takes, the adjustment is declared as successful. Table II shows the successfully estimated parameters (highlighted) using the planned tie-point grid of $1 \times 5 \mathrm{~km}$ for different ground control point configurations and under different noise conditions. Note, that for this table the maximum difference between simulated and adjusted height error is averaged over all data takes. Note also, that in this case only the estimated parameters were simulated. Table II shows that offsets can almost always be estimated. To determine the tilts, we need a ground control point grid of at least $100 \mathrm{~km}$, and then noise must not be higher than $0.7 \mathrm{~m}$. For estimating higher order polynomials, we need a great number of GCPs. In addition to the results presented in Table II we can state that a tie-point grid of $1 \times 5 \mathrm{~km}$ is dense enough and one crossing orbit improves the estimation of parameter $b$ (tilt in range). Increasing the number of crossing orbits does not improve the determinability of other parameters.

Finally, it has to be mentioned, that although the adjusted height error model fits the simulated one very well, single parameters, their standard deviations and significances are very bad, especially for configurations with only few ground control points and for higher order polynomial coefficients. This is due to the fact, that the simulated parameters are very small $(0.5 \mathrm{~m})$ proportional to noise $(0.4-2 \mathrm{~m})$. Thus distinguishing between parameter $\mathrm{c}$, e and $f$ is difficult. Further investigations will focus on verification methods for adjustment results.

\subsection{Adjustment results on E-SAR data}

Additionally, the DEM adjustment concept is evaluated on real data. Therefore, two overlapping E-SAR DEMs near the Alps in Germany with an extension of $4 \times 15 \mathrm{~km}$ were used (Fig. 4, left). Each DEM was distorted according to Eq. (1) and with an additional quadratic component in range, as shown in Fig. 4. In the adjustment ICESat heights were introduced as reference data. Because of the great magnitude of the errors up to $30 \mathrm{~m}$ all parameters could be estimated. Fig. 4 (right) shows the adjusted heights of strip 1 after applying the correction function. An evaluation with GPS-track data also confirms the improvements. In flat areas the requirement of $2 \mathrm{~m}$ relative accuracy could be fulfilled.
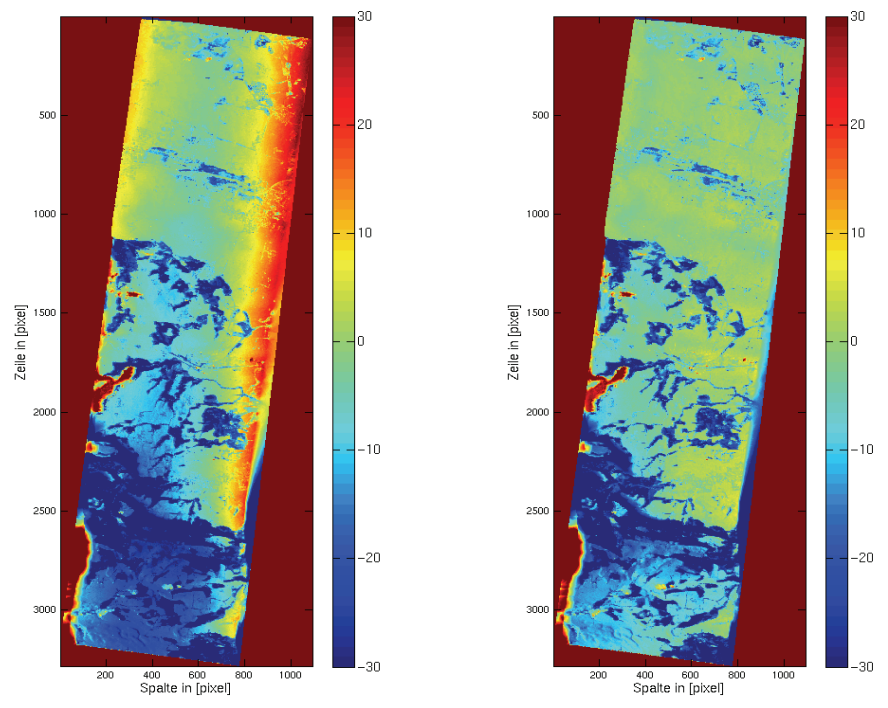

Figure 4. E-SAR DEM differences to a LaserDEM: before and after adjustment

\section{CONCLUSION}

The design of the calibration of DEM datatakes for the TanDEM-X mission is described in this paper. It outlines the main features of a least-squares adjustment of DEMs to ensure the required accuracies and shows first results on simulated and real distorted DEM data.

Finally, we would like to thank the E-SAR team at DLR-HR for providing the E-SAR DEMs.

\section{REFERENCES}

[1] G. Krieger, A. Moreira, H. Fiedler, I. Hajnsek, M. Werner, M. Younis, M. Zink: "TanDEM-X: A Satellite Formation for High Resolution SAR Interferometry," TGRS, 45(11), pp. 3317 - 3341, 2007.

[2] B. Wessel, U. Marschalk, A. Gruber, M. Huber, T. Hahmann, A. Roth, M. Habermeyer, D. Kosmann: "Design of the DEM Mosaicking and Calibration Processor for TanDEM-X," Proc. of EUSAR 2008, Friedrichshafen, Germany, 2008.

[3] J. Abshire, X. Sun, H. Riris, J. Sirota, M. McGarry, S. Palm, D. Yi, and P. Liiva: "Geoscience Laser Altimeter System (GLAS) on the ICESat Mission: On-orbit measurement performance", Geophysical Research Letters, Vol. 32, 2005. 